Have Sports Venues Mitigated

The Home Foreclosure Crisis?

by

Paul M. Sommers

June 2010

MIDDLEBURY COLLEGE ECONOMICS DISCUSSION PAPER NO. 10-25

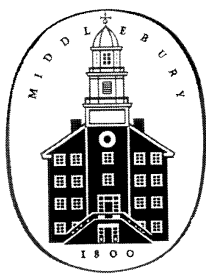

DEPARTMENT OF ECONOMICS

MIDDLEBURY COLLEGE

MIDDLEBURY, VERMONT 05753

http://www.middlebury.edu/ econ 
HAVE SPORTS VENUES MITIGATED

THE HOME FORECLOSURE CRISIS?

by

Paul M. Sommers

Department of Economics

Middlebury College

Middlebury, Vermont 05753

JEL \#: L83, L85 


\section{HAVE SPORTS VENUES MITIGATED THE HOME FORECLOSURE CRISIS?}

While many other people have already studied the impact of sports venues on local income and employment growth, this brief research note examines their impact on foreclosure rates in the county the venue is located in. If these facilities are truly the catalysts for economic development on their periphery as some have claimed, then foreclosure rates should be no higher (and possibly significantly lower) in counties with these venues compared to counties without them.

All but ten of the 114 U.S. teams in the four major North American professional sports leagues [baseball’s MLB (29 U.S. teams), basketball’s NBA (29), ice hockey’s NHL (24), and football's NFL (32)] are located in the 100 largest counties by population as of July 2009 (www.census.gov/popest/counties/CO-EST2009-07.html) . The ten exceptions are located in six less populous counties: Saint Louis City County, MO [St. Louis Cardinals (MLB), St. Louis Blues (NHL), St. Louis Rams (NFL)]; District of Columbia [Washington Nationals (MLB), Washington Wizards (NBA)]; Orleans, LA [New Orleans Hornets (NBA), New Orleans Saints (NFL)]; Arlington, VA [Washington Capitals (NHL)]; Ramsey, MN [Minnesota Wild (NHL)]; and Brown, WI [Green Bay Packers (NFL)]. The zip code for each team’s facility can be used to find the county in which it is located (using www.naco.org). There was at least one team from one of the four major sports leagues in 57 of the 106 counties. The counties were then divided into four Census regions: West (26 of the 106 total); Midwest (19); Northeast (26); and South (35). Foreclosure rates for each county were found by dividing the number of foreclosures as of the first week of June 2010 (www.realtytrac.com/mapsearch/) by the latest available estimates of owner-occupied housing units in each county (based on the 2006-2008 American Community Survey at www.factfinder.census.gov/). Within each Census region, one can compare (using a 
two-sample $t$-test) the average foreclosure rate in counties with and without a professional baseball, basketball, ice hockey, or football team.

In the West Census region, the average foreclosure rate in counties with a sports team in any one of the four individual major sports leagues was lower than the average foreclosure rate in counties without a similarly described team. But, in no case were the differences statistically significant [MLB $(p=.345)$; NBA $(p=.967)$; NHL $(p=.887)$; and NFL $(p=.414)]$. In all three other Census regions (Midwest, Northeast, and South), counties with a team had, on average, in all but two cases higher foreclosure rates than counties without a team. The two exceptions both involved the NFL. Counties in the Midwest and Northeast with an NFL team had a lower average foreclosure rate than their counterparts without an NFL team, but in neither case was the difference significant. Only two of the twelve comparisons (four sports leagues in each of the three Census regions other than the West) were marginally significant: Northeast counties with a baseball (MLB) team had a higher average foreclosure rate $(p=.053)$ and Midwest counties with a basketball (NBA) team also had a higher average foreclosure rate $(p=.053)$ than their counterparts without a team.

When counties with a major sports team in one Census region were compared to counties with a team in the same sports league in another Census region, all of the comparisons that were statistically significant favored just one Census region: the Northeast. For counties that are home to an MLB (NHL) team, foreclosure rates were, on average, lower in the Northeast than they were in the Midwest $[p=.025(p=.078)]$ and in the West $[p=.085(p=.076)]$. For counties that are home to an NBA (NFL) team, foreclosure rates were, on average, lower in the Northeast than they were in the Midwest $[p=.007(p=.004)]$, the West $[p=.013(p=.066)]$, and the South $[p=.100(p=.012)]$

In summary, host counties in only the West Census region had lower (but not significantly lower) foreclosure rates than counties without a team in all four major sports leagues. In comparisons involving the three other Census regions, foreclosure rates were, on average, 
higher (and, in several cases, significantly higher) than they were in counties without a team in the same sports league. And, among counties with a sports team, the Northeast experienced lower foreclosure rates. 